\title{
Effect of 1,4-Naphthalenedicarboxylic Acid Derivative on Crystallization and Performances of Poly(L-lactide)
}

\author{
LISHA ZHAO ${ }^{1}$, JUN QIAO ${ }^{1}$, XUELING SHAN ${ }^{1,2}$, YANHUA CAI ${ }^{1,2 *}$, JIE ZHANG ${ }^{1}$ \\ ${ }^{1}$ Chongqing Key Laboratory of Environmental Materials \& Remediation Technologies, College of Chemistry and \\ Environmental Engineering, Chongqing University of Arts and Sciences, Chongqing-402160, P.R. China \\ ${ }^{2}$ School of Petrochemical Engineering, Changzhou University, Changzhou, Jiangsu-213164, P.R. China
}

\begin{abstract}
In this work, biodegradable Poly(L-lactide) (PLLA) was modified through adding a new organic additive $N, N^{\prime}$-bis(benzoyl) 1, 4-naphthalenedicarboxylic acid dihydrazide (NABH). A comparison on crystallization of the pure PLLA and PLLA/NABH revealed that the NABH as effective heterogeneous nucleation sites enhanced PLLA's crystallization, and an increase of NABH loading was able to further accelerate crystallization rate of PLLA; whereas a faster cooling rate was not conducive to PLLA's crystallization, but the appearance of obvious crystallization peak upon cooling at $30^{\circ} \mathrm{C} / \mathrm{min}$ confirmed the advanced enhancing role of NABH for PLLA crystallization again. The investigation on influence of the final melting temperature on the crystallization behavior of PLLA showed that the 170 ${ }^{\circ} \mathrm{C}$ was optimum final melting temperature for enhancing crystallization, even the onset crystallization temperature of PLLA/NABH were higher than $150^{\circ} \mathrm{C}$. The melting processes of PLLA/NABH after different crystallization not only could reflect the previous crystallization, but also depended on crystallization temperature and heating rate. Thermal decomposition results showed that the existence of NABH slightly weakened thermal stability of PLLA, and the maximum difference in onset thermal decomposition temperature was only $9.4^{\circ} \mathrm{C}$ comparing with the pure PLLA. However, the presence of NABH in PLLA matrix seriously weakened optical property.
\end{abstract}

Keywords: poly(L-lactide), benzoic hydrazide, nucleation effect, melt-crystallization, thermal stability

\section{Introduction}

Solid waste pollution from the fossil-based and non-degradable polymeric products has led to a severe crisis for promoting social sustainable development, what is worse, up to now, the large-scale usage of non-degradable polymeric products has not been still reduced. Inevitably, developing bio-based and degradable polymeric materials as fossil-based polymers substitutions has become an important researching hotspot [1]. Poly(L-lactide) (PLLA) produced from renewable sources is widely known as a commercially available thermoplastic [2] with excellent degradability and compatibility [3, 4], easy processing [1, 5], appropriate mechanical performances [6,7], etc. These advantages endow PLLA with promising applications in different fields, mostly for packaging materials [8-10], biomedical materials [11-13] and 3D printing materials [14-16]. For instance, to develop degradable carrier for controlled drug delivery, Li et al [17] prepared the polylactic acid composite membranes containing zeolitic imidazolate framework- 8 via secondary growth method, the relative results indicated that the zeolitic imidazolate framework-8/polylactic acid composite membranes possessed excellent drug release and $p \mathrm{H}$ response capacity, and over $90 \%$ of loaded drug could be released in the buffer of $p \mathrm{H}$ value of 7.4.

However, the inherent drawbacks of high cost, slow crystallization rate, poor heat resistance and low crystallinity $[2,18]$ seriously restrict the practical demanding applications of PLLA. Among aforementioned drawbacks, both poor heat resistance and low crystallinity result from the slow crystallization rate, additionally, the slow crystallization rate also affects PLLA's mechanical properties via forming amorphous products with low strength and modulus as well as poor dimensional stability [6]. Therefore, accelerating crystallization of PLLA is extremely important to remedy the performance defects of PLLA and thoroughly realize the replacement of the conventional fossil-based thermoplastic. Adding physical nucleating agent is thought to be an easy industrialization way to accelerate crystalli-

\footnotetext{
*email: mci651@163.com
} 
zation rate of semi-crystalline polymers, which is also suitable for PLLA. In the early research, the crystallization accelerating agent for PLLA focused on the commercial nucleating agents for other polymers such as polypropylene and polyethylene, these typical additives included clay [19-21], ethylene bis stearamide [20], calcium carbonate [22, 23], etc. After that, with the in-depth research, more inorganic or organic compounds including commercial or newly-synthesized compounds were employed to estimate their roles in enhancing PLLA's crystallization, and the relative results showed that metal phosphonates [24,25], inorganic whiskers [26,27], nano-inorganic matter [28,29], benzhydrazide derivatives [30,31], sorbitol derivatives [32,33] and 1H-benzotriazole derivatives [34] were highly effective nucleating agents for crystallization.

Through analysis, it is found that, in comparison to inorganic nucleator, the organic nucleator has attracted increasing attentions due to the better compatibility with PLLA and flexible designability of molecular structure. However, it is still unclear which key organic groups can affect the crystallization nucleation effect according to a finite category and quantity of the current organic nucleating agents. Thus, in this work, a new organic compound named $N$, $N$ '-bis(benzoyl) 1, 4-naphthalenedicarboxylic acid dihydrazide (NABH) was developed to estimate its influences on the crystallization process, melting process, thermal decomposition behavior and optical property of PLLA. This work will be helpful to enrich the amount of organic nucleating agent and explore nucleation mechanism according to the relative key structure.

\section{Materials and methods \\ Materials and reagents}

A commercial grade 4032D PLLA produced by Nature-Works LLC was adopted. All reagents used to synthesis NABH were required to be analytically pure and directly used as received without purification before usage; these relative reagents included 1, 4-naphthalenedicarboxylic acid, benzoic hydrazide, $N, N^{\prime}$-dimethylformamide (DMF), thionyl chloride and pyridine.

\section{Synthesis of NABH}

The synthetic pathway of NABH is shown in Figure 1. A detailed synthetic route is following: $9 \mathrm{~g}$ 1, 4-naphthalenedicarboxylic acid and $1 \mathrm{~mL}$ DMF as catalyst were added into a three-necked flask with $60 \mathrm{~mL}$ thionyl chloride, respectively. And then with increasing of temperature to $80^{\circ} \mathrm{C}$, the solid-state 1 , 4-naphthalenedicarboxylic acid was gradually dissolved in thionyl chloride with stirring, the aforementioned mixed solution were stirred at $80^{\circ} \mathrm{C}$ for $36 \mathrm{~h}$, after that, 1, 4-naphthalenedicarboxylic acid dichloride was obtained via vacuum distillation. The 1, 4-naphthalenedicarboxylic acid dichloride was subsequently added into a solution including $0.006 \mathrm{~mol}$ benzoic hydrazide, $100 \mathrm{~mL}$ DMF and $3 \mathrm{~mL}$ pyridine, the mixture was stirred at ice bath for $1.5 \mathrm{~h}$, heated up to $60^{\circ} \mathrm{C}$ to keep stirring for $3 \mathrm{~h}$, the resulting solution was poured into $300 \mathrm{~mL}$ distilled water, the crude product was obtained by filtration method, and the crude product was further washed by distilled water for three times to obtain the final white product NABH. Fourier Transform Infrared Spectrometer (FT-IR) $v: 3448.2 \mathrm{~cm}^{-1}(\mathrm{~N}-\mathrm{H}$ stretching vibrations absorption), 3173.7 and $688.9 \mathrm{~cm}^{-1}$ (C-H stretching vibration and the out-of-plane bending vibration absorption), $1654.1 \mathrm{~cm}^{-1}$ (stretching vibration absorption of $\mathrm{C}=\mathrm{O}$ of synthesized amide), $1630.4 \mathrm{~cm}^{-1}$ (stretching vibration absorption of $\mathrm{C}=\mathrm{O}$ of benzoic hydrazide), 1597.3, 1575.4, 1496.3 and $1442.6 \mathrm{~cm}^{-1}$ (vibration absorption of $\mathrm{C}-\mathrm{C}$ of benzene and naphthalene), $1473.6 \mathrm{~cm}^{-1}$ (C-N-H bending vibration absorption), $1351.1 \mathrm{~cm}^{-1}$ (the mixed absorption about stretching vibration of $\mathrm{C}-\mathrm{N}$ and bending vibration of $\mathrm{N}-\mathrm{H}$ ), 870.1 and $829.5 \mathrm{~cm}^{-1}$ (out-of-plane bending vibration absorption of $\mathrm{C}-\mathrm{H}$ of aromatic hydrocarbon), $710.0 \mathrm{~cm}^{-1}$ (N-H out-of-plane bending absorption); ${ }^{1} \mathrm{H}$ Nuclear Magnetic Resonance $\left({ }^{1} \mathrm{H}\right.$ NMR) $\delta$ : ppm; 10.69 (s 1H, NH), 10.60 (s, 1H, NH), 8.49 8.51 (m, 1H, Py), 7.99 8.01 (d, 2H, Py), 7.54 7.76 (m, 5H, Ar). 


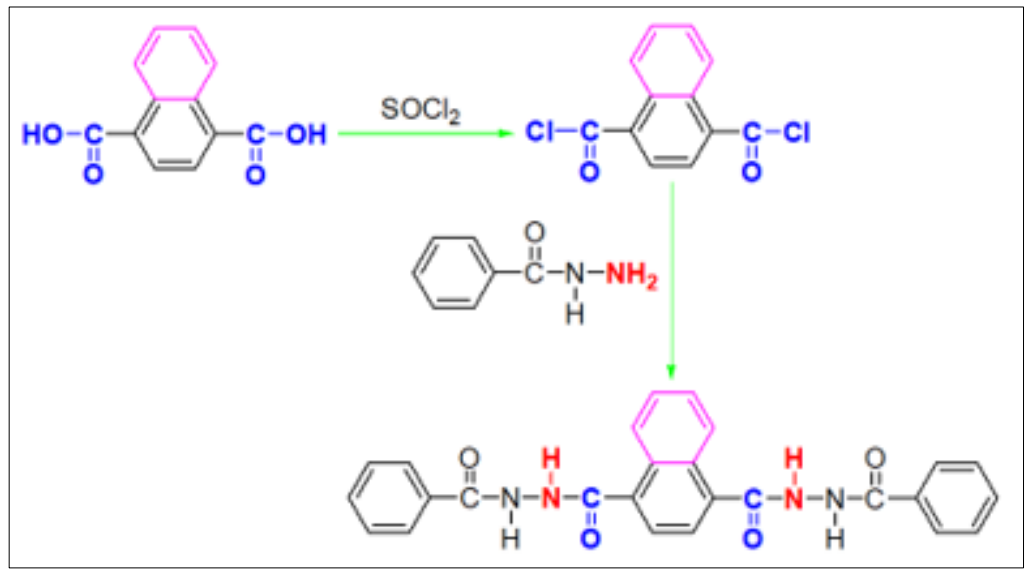

Figure 1. Synthetic pathway of NABH

\section{Preparation of PLLA/NABH}

First, PLLA and NABH were dried in vacuum at $45^{\circ} \mathrm{C}$ for $24 \mathrm{~h}$ to avoid the influence of water on the high temperature blending of PLLA with NABH. Second, The PLLA containing various NABH concentrations $(0,0.5,1,2$ and $3 \mathrm{wt} \%)$ was blended on a torque rheometer, and the melt-blending temperature was set at $190^{\circ} \mathrm{C}$; the blending rotation speed was set to be $32 \mathrm{rpm}$ for $7 \mathrm{~min}$, and then further increased to $64 \mathrm{rpm}$ for $7 \mathrm{~min}$. After that, the aforementioned mixture was hot pressed by $20 \mathrm{MPa}$ pressure at $180^{\circ} \mathrm{C}$, followed by cool-pressing at room temperature to obtain sample with a thickness of $0.4 \mathrm{~mm}$ to perform the relevant tests.

\section{Test}

Both crystallization and melting processes of the pure PLLA and modified PLLA were recorded by Q2000 DSC with $50 \mathrm{~mL} / \mathrm{min}$ nitrogen. Although the testing conditions of crystallization and melting behaviors were different, the temperature and heat flow firstly needed to be calibrated using an indium standard before testing, and the thermal history also needed to be eliminated to ensure the relative tests at the same level. Under atmospheric condition, a Q500 TGA was used to perform a comparison test on thermal decomposition of the pure PLLA and modified PLLA, the testing temperature was from $40^{\circ} \mathrm{C}$ to $650^{\circ} \mathrm{C}$ with a heating rate of $5^{\circ} \mathrm{C} / \mathrm{min}$. The light transmittance was determined by the average value of the 5 times measurements using a DR82 transmittance instrument.

\section{Results and discussions \\ Crystallization process}

Upon cooling at $1{ }^{\circ} \mathrm{C} / \mathrm{min}$, the DSC thermograms of the pure PLLA and modified PLLA were displayed in Figure 2, and the relative crystallization parameters were listed in Table 1. As shown in Figure 2, DSC thermograms of the pure PLLA is clearly indicative of no melt-crystallization peak detected, indicating that, although that the cooling rate of $1^{\circ} \mathrm{C} / \mathrm{min}$ is very slow, the pure PLLA cannot still form crystal in cooling via homogeneous nucleation, this finding confirms PLLA's poor crystallization ability as reported $[35,36]$. In contrast with the pure PLLA, the melt-crystallization peaks of all PLLA/NABH samples can be easily detected in DSC thermograms, furthermore, the meltcrystallization peaks observed in DSC thermograms are very sharp, suggesting that the presence of $\mathrm{NABH}$ as effective heterogeneous nucleation sites is able to enhance crystallization ability and accelerate crystallization rate of PLLA. Additionally, Figure 2 displays the effect of NABH loading on the crystallization process of PLLA. Compared to the other three NABH loading, with the addition of 1 wt $\% \mathrm{NABH}$, the PLLA/1\% NABH has the highest onset crystallization temperature $\left(T_{o c}\right)$ of $142.3^{\circ} \mathrm{C}$, crystallization peak temperature $\left(T_{m c}\right)$ of $138.2^{\circ} \mathrm{C}$, and the melting temperature $\left(T_{m}\right)$ of $169.4^{\circ} \mathrm{C}$, as well as the largest crystallization enthalpy $\left(\Delta H_{c}\right)$ of $48.9 \mathrm{~J} / \mathrm{g}$, showing that $1 \mathrm{wt} \% \mathrm{NABH}$ is the optimal loading for inducing crystallization of PLLA. However, the temperature difference $\left(\Delta T_{c}\right)$ between $T_{o c}$ and $T_{m c}$ is 
not the minimum value, which implies that the crystallization rate of PLLA/1\%NABH is not the fastest in cooling, because a samller $\Delta T_{c}$ often means the faster crystallization rate. For the other three NABH loading of $0.5 \mathrm{wt} \%, 2 \mathrm{wt} \%$ and $3 \mathrm{wt} \%$, an increase of NABH loading leads to a shift of crystallization peak to higher temperature side because of an increase of heterogeneous nucleation density in PLLA matrix; as seen in Table. 1 , the $T_{o c}$ and $T_{m c}$ increase from $137.7^{\circ} \mathrm{C}$ and $133.1^{\circ} \mathrm{C}$ to $139.4^{\circ} \mathrm{C}$ and $136.2^{\circ} \mathrm{C}$, respectively; meanwhile the $\Delta T_{c}$ decreases from $4.6^{\circ} \mathrm{C}$ to $3.2^{\circ} \mathrm{C}$, this drop in $\Delta T_{c}$ confirms that the NABH can accelerate PLLA's crystallization rate again. Overall, the addition of NABH can significantly promote the PLLA's crystallization in cooling, but the effect of NABH loading on the crystallization may depend not only on the NABH loading, but also the migration of PLLA chain segment.

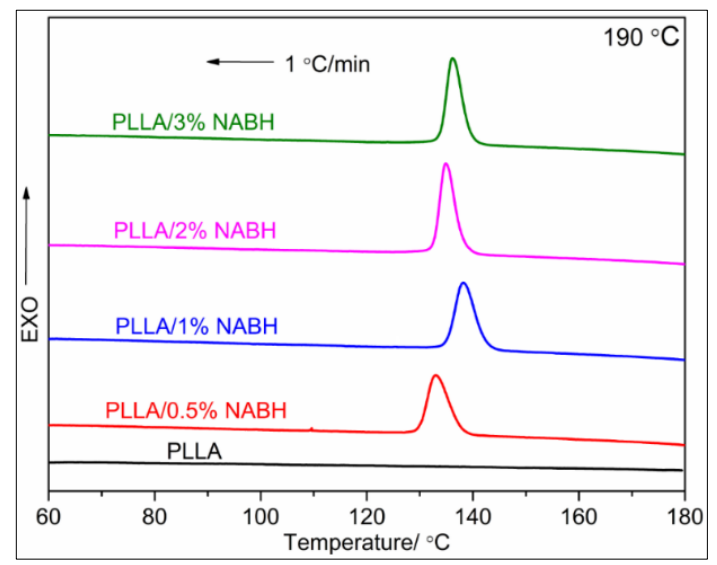

Figure 2. DSC thermograms of the pure

PLLA and PLLA/NABH from the melt of $190^{\circ} \mathrm{C}$ at $1^{\circ} \mathrm{C} / \mathrm{min}$

Table 1. Crystallization DSC parameters of PLLA/NABH from the melt of $190{ }^{\circ} \mathrm{C}$ at $1{ }^{\circ} \mathrm{C} / \mathrm{min}$

\begin{tabular}{|c|c|c|c|c|c|}
\hline Sample & $T_{o c} /{ }^{\circ} \mathrm{C}$ & $T_{m c} /{ }^{\circ} \mathrm{C}$ & $\Delta T_{c} /{ }^{\circ} \mathrm{C}$ & $\Delta H_{c} / \mathrm{J} / \mathrm{g}$ & $T_{m} /{ }^{\circ} \mathrm{C}$ \\
\hline PLLA/0.5\%NABH & 137.7 & 133.1 & 4.6 & 48.3 & 168.0 \\
\hline PLLA/1\%NABH & 142.3 & 138.2 & 4.1 & 48.9 & 169.4 \\
\hline PLLA/2\%NABH & 138.1 & 134.9 & 3.2 & 48.4 & 168.4 \\
\hline PLLA/3\%NABH & 139.4 & 136.2 & 3.2 & 47.7 & 168.6 \\
\hline
\end{tabular}

$T_{m}: T_{m}$ was obtained during the second heating at a heating rate of $10^{\circ} \mathrm{C} / \mathrm{min}$

Evaluating crystallization ability of the modified PLLA at a higher cooling rate is necessary to practical production, because an increase of cooling rate often weakens the ability of additives for enhancing PLLA crystallization [37-39]. Figure 3 depicts the crystallization processes of PLLA/NABH from $190^{\circ} \mathrm{C}$ at various cooling rates $\left(5,10,20\right.$ and $\left.30^{\circ} \mathrm{C} / \mathrm{min}\right)$. For a given PLLA/NABH sample, it is observed that a wider melt-crystallization peak located at lower temperature side appears in the DSC curve with an increase of cooling rate, suggesting a relative weaker crystallization ability and a relative slower crystallization rate. Even then, all PLLA/NABH still have obvious crystallization peaks at all cooing rates, even the NABH is still able to accelerate the PLLA's crystallization rate upon cooling at $30^{\circ} \mathrm{C} / \mathrm{min}$, which further confirms the advanced crystallization accelerating role of NABH. Additionally, upon cooling at a higher cooling rate, it is noteworthy that a larger NABH loading have a greater inhibition for preventing the weakness of crystallization ability as shown in Figure 3, the reason is that a larger amount of NABH can provide a higher nucleation density in PLLA matrix and cause meltcrystallization to occur at a relative higher temperature, which be proved by the crystallization peak shift toward higher temperature side with the increase in NABH loading in PLLA matrix. 

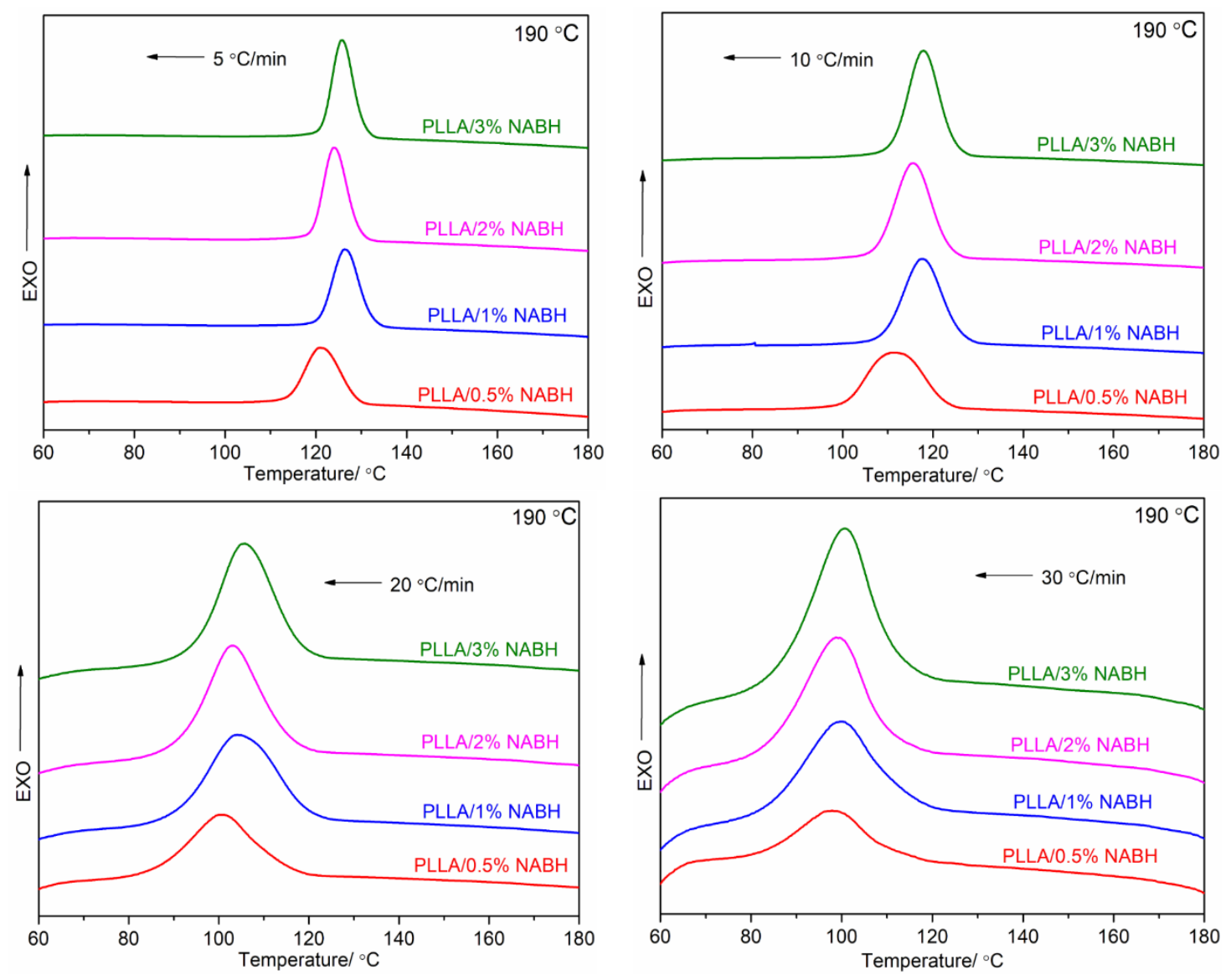

Figure 3. DSC thermograms of PLLA/NABH from $190^{\circ} \mathrm{C}$ at various cooling rates

The final melting temperature $\left(T_{f}\right)$ determines solubility of NABH in PLLA resin according to the principle of "like dissolves like", correspondingly the $T_{f}$ must affect the crystallization processes of PLLA/NABH in cooling. Figure 4 shows the DSC thermograms of PLLA/NABH from different $T_{f}$ at a cooling rate of $1^{\circ} \mathrm{C} / \mathrm{min}$, and the relative crystallization parameters are listed in Table 2. As shown in Figure 4 , the crystallization processes are significantly affected by $T_{f}$. When the $T_{f}$ is $170^{\circ} \mathrm{C}$, the crystallization peak moves toward the higher temperature side with the increase in NABH concentration, which is different from the results about the influence of NABH loading on the crystallization behaviors from other $T_{f}$ at a cooling rate of $1^{\circ} \mathrm{C} / \mathrm{min}$. Moreover, Table. 1 indicates that the $T_{f}$ of $170^{\circ} \mathrm{C}$ is conducive to crystallize because of the presence of the highest $T_{o c}$ and $T_{m c}$ and the largest $\Delta H_{c}$, the probable reason is that, on the hand, the relative low $T_{f}$ in this study can provide the PLLA chain segment with excellent motility to ensure crystal growth; on the other hand, the relative low $T_{f}$ can avoid the destruction of crystal stability resulting from the high temperature, as well as $T_{f}$ of $170^{\circ} \mathrm{C}$ can ensure a larger amount of undissolved $\mathrm{NABH}$ as heterogeneous nucleus in PLLA matrix. Under this circumstance, PLLA/NABH have fast nucleation rate and crystal growth rate. As a result, the crystallization is completed in the higher temperature region. Additionally, it is noted that the $T_{o c}$ of PLLA/2\%NABH and $\mathrm{PLLA} / 3 \% \mathrm{NABH}$ are higher than $150^{\circ} \mathrm{C}$, which is rather close to the melting range of the pure $4032 \mathrm{D}$ PLLA (about $160 \sim 175^{\circ} \mathrm{C}$ [40]), this result confirms the powerful crystallization ability of PLLA/NABH again. When the $T_{f}$ is increased to $190^{\circ} \mathrm{C}$, a given PLLA/NABH sample has the minimum $T_{o c}, T_{m c}$ and $\Delta H_{c}$, but the $T_{o c}, T_{m c}$ and $\Delta H_{c}$ gradually increase when further increasing $T_{f}$ to $200^{\circ} \mathrm{C}$, this effect may depend on the interaction of PLLA with undissolved NABH, because an increase of $T_{f}$ must dissolve more NABH in PLLA matrix, and these dissolved NABH can enhance the compatibility and interaction of PLLA with undissolved NABH, resulting in the fast and ordered arrangement of PLLA molecular chains. 


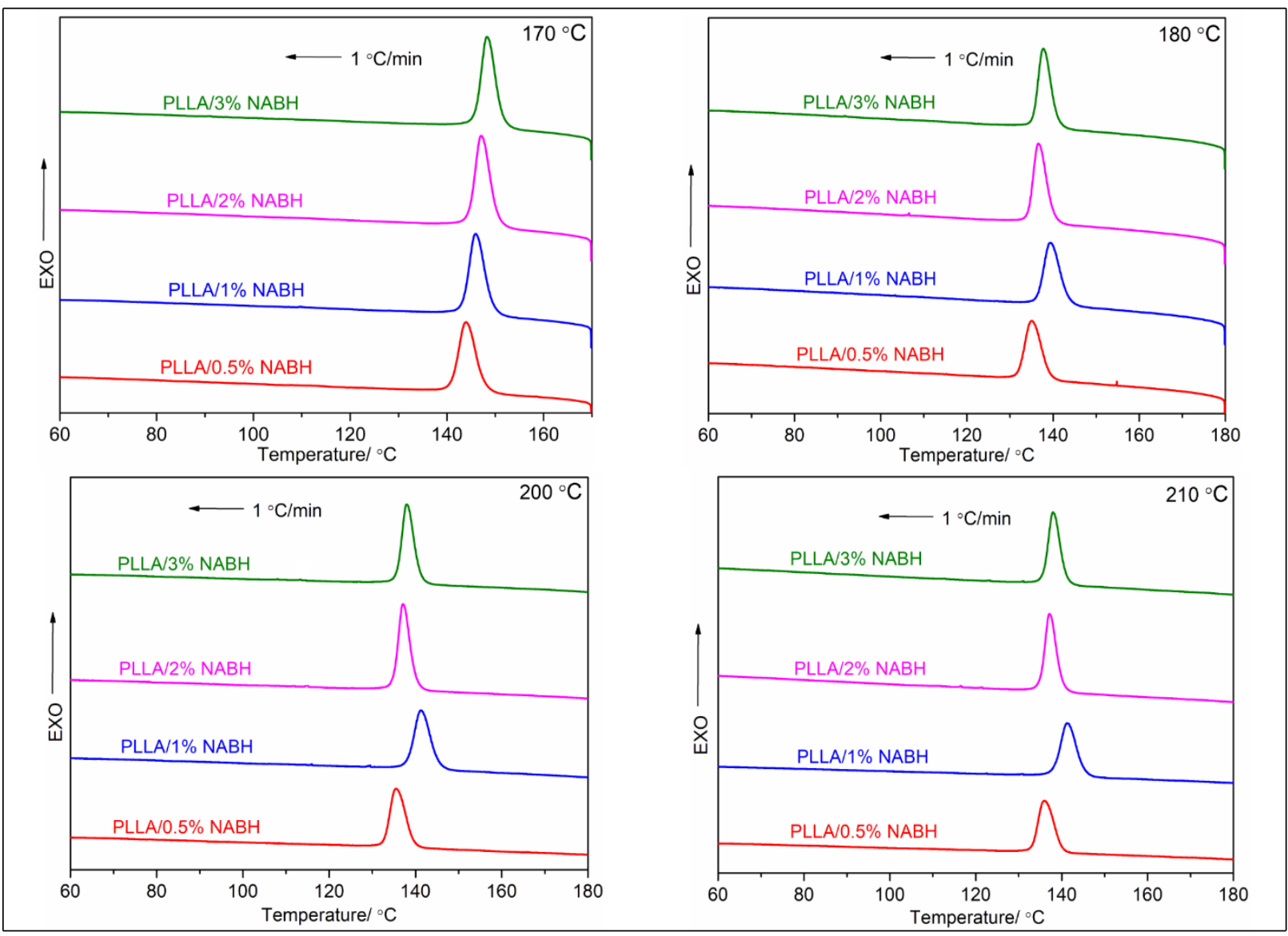

Figure 4. DSC thermograms of PLLA/NABH from various $T_{f}$ at $1{ }^{\circ} \mathrm{C} / \mathrm{min}$

Table 2. Crystallization DSC parameters of PLLA/NABH samples from various $T_{f}$ at $1{ }^{\circ} \mathrm{C} / \mathrm{min}$

\begin{tabular}{|c|c|c|c|c|c|c|}
\hline$T_{f} /{ }^{\circ} \mathrm{C}$ & Sample & $\mathrm{T}_{o c} /{ }^{\circ} \mathrm{C}$ & $\boldsymbol{T}_{m c} /{ }^{\circ} \mathrm{C}$ & $\Delta T_{c} /{ }^{\circ} \mathrm{C}$ & $\Delta H_{c} / \mathrm{J} / \mathrm{g}$ & $T_{m} /{ }^{\circ} \mathrm{C}$ \\
\hline \multirow{4}{*}{170} & PLLA/0.5\%NABH & 147.8 & 144.0 & 3.8 & 54.7 & 171.2 \\
\hline & PLLA/1\%NABH & 149.5 & 145.9 & 3.6 & 55.4 & 171.9 \\
\hline & PLLA/2\%NABH & 150.5 & 147.1 & 3.4 & 55.1 & 172.1 \\
\hline & PLLA/3\%NABH & 151.5 & 148.3 & 3.2 & 53.5 & 172.3 \\
\hline \multirow{4}{*}{180} & PLLA/0.5\%NABH & 139.1 & 135.0 & 4.1 & 51.2 & \\
\hline & PLLA/1\%NABH & 143.6 & 139.4 & 4.2 & 52.3 & 169.5 \\
\hline & PLLA/2\%NABH & 140.1 & 136.6 & 3.5 & 50.3 & 168.7 \\
\hline & PLLA/3\%NABH & 141.1 & 137.7 & 3.4 & 52.2 & 168.8 \\
\hline \multirow{4}{*}{200} & PLLA/0.5\%NABH & 139.6 & 135.5 & 4.1 & 53.0 & 167.8 \\
\hline & PLLA/1\%NABH & 145.3 & 141.3 & 4.0 & 55.1 & 169.4 \\
\hline & PLLA/2\%NABH & 140.1 & 137.1 & 3.0 & 53.8 & 168.0 \\
\hline & PLLA/3\%NABH & 141.1 & 138.0 & 3.1 & 53.6 & 168.3 \\
\hline \multirow{4}{*}{210} & PLLA/0.5\%NABH & 140.0 & 136.0 & 4.0 & 54.0 & 167.9 \\
\hline & PLLA/1\%NABH & 145.2 & 141.3 & 3.9 & 55.2 & 169.0 \\
\hline & PLLA/2\%NABH & 140.1 & 137.2 & 2.9 & 55.5 & 167.8 \\
\hline & PLLA/3\%NABH & 141.0 & 138.0 & 3.0 & 53.7 & 168.1 \\
\hline
\end{tabular}




\section{Melting behavior}

Usually, the melting behavior of semi-crystalline polymers depends on their crystallinity and crystal perfection. Figure 5 is DSC thermograms of PLLA/NABH at various heating rates $\left(1,2,5\right.$ and $\left.10^{\circ} \mathrm{C} / \mathrm{min}\right)$ after melt-crystallization at $1{ }^{\circ} \mathrm{C} / \mathrm{min}$. It can be observed from Figure 5 that, upon heating at $1{ }^{\circ} \mathrm{C} / \mathrm{min}$, the PLLA/ $0.5 \% \mathrm{NABH}$ has double melting peaks, the reason is that the rather slow heating rate of $1^{\circ} \mathrm{C} /$ min can further promote crystallization to occur, when the previous melt-crystallization cannot be thoroughly completed. However, it should be note that the high-temperature side melting peak is in the form of the shoulder peak, indicating that the amount of recrystallized crystals is very low. Upon heating at other rates, all PLLA/NABH only have the single melting peak, but the melting peak of a given PLLA/NABH becomes wider with an increase of heating rate due to the thermal hysteresis.

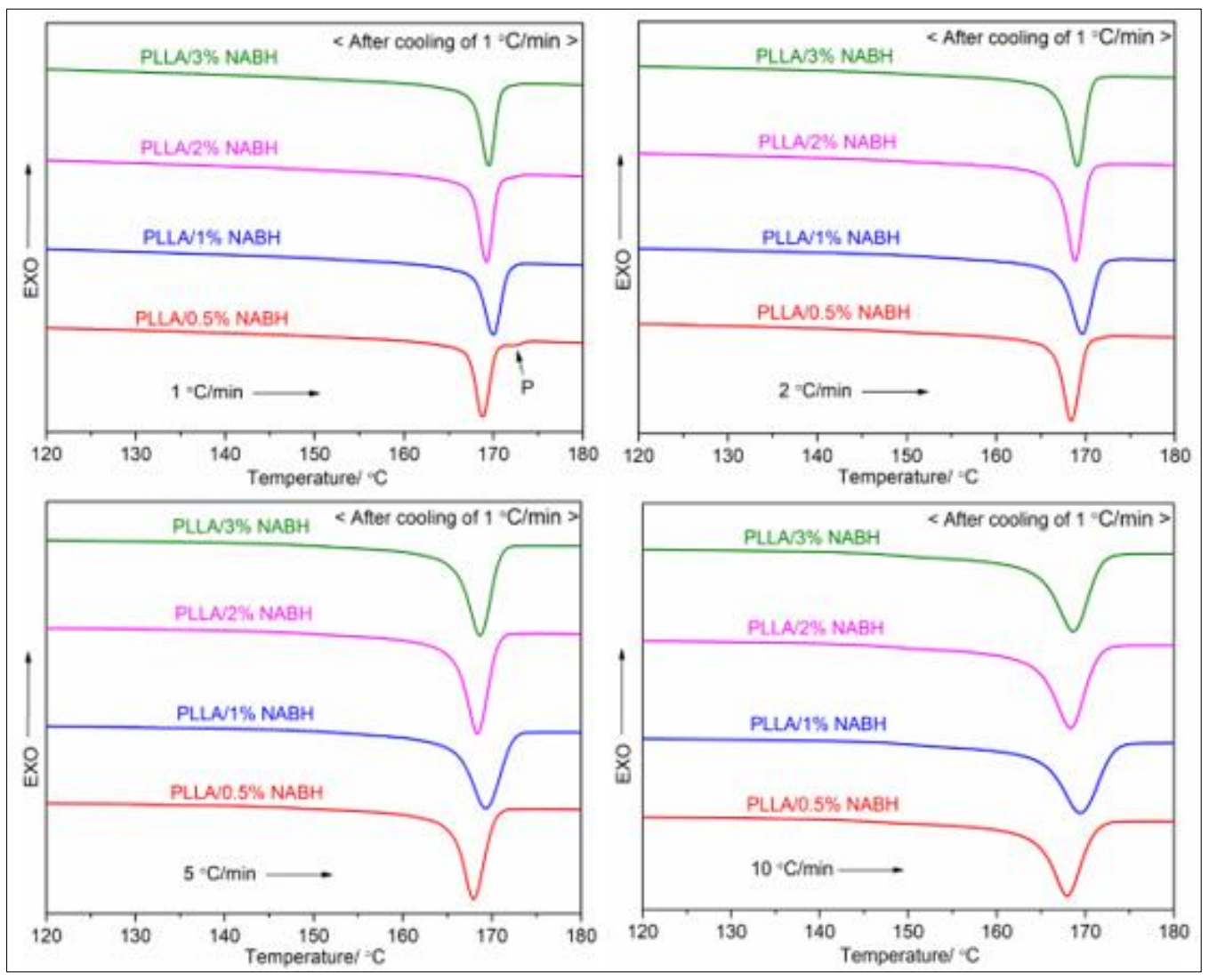

Figure 5. Melting behaviors of PLLA/NABH at various heating rates after melt-crystallization at $1{ }^{\circ} \mathrm{C} / \mathrm{min}$

In melt-crystallization section, the $T_{m c}$ of all PLLA/NABH are about $130{ }^{\circ} \mathrm{C} \sim 140^{\circ} \mathrm{C}$, meaning the crystallization rate is the fastest in this temperature region. Thus, the melting behaviors of PLLA/NABH after isothermal crystallization in the temperature range of $130^{\circ} \mathrm{C} \sim 140{ }^{\circ} \mathrm{C}$ were further studied by DSC, Figure. 6 is the heating processes of PLLA/NABH at $10^{\circ} \mathrm{C} / \mathrm{min}$ after isothermal crystallization at various crystallization temperatures $\left(130,132,134,136,138\right.$ and $\left.14^{\circ} \mathrm{C}\right)$ for $180 \mathrm{~min}$. As isothermal crystallization temperature increases from $130^{\circ} \mathrm{C}$ to $140^{\circ} \mathrm{C}$, there are two typical features in DSC curves, one feature is that all PLLA/NABH exhibit the single melting peak, showing that the crystallization has been completed after sufficient crystallization for $180 \mathrm{~min}$; another feature is that the single melting peak moves toward the higher temperature side with increasing of crystallization temperature, because a higher crystallization temperature can cause the crystal to grow more perfect. 


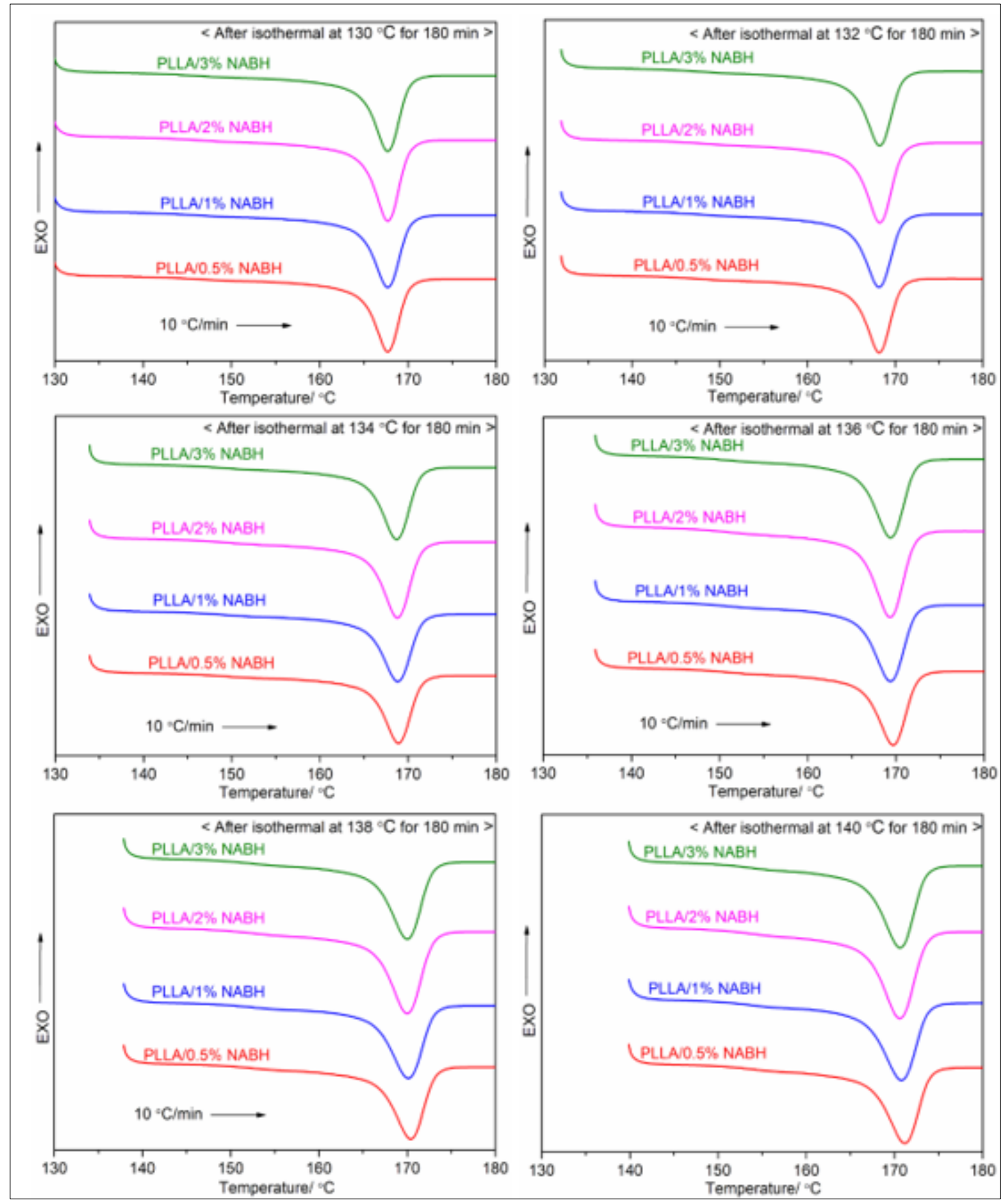

Figure 6. Melting behaviors of PLLA/NABH at the heating rate of $10^{\circ} \mathrm{C} / \mathrm{min}$ after isothermal crystallization

\section{Thermal stability and optical property}

For practical application, investigating on the thermal decomposition behavior in air is very necessary to adapt for various applications. Hence, Figure 7 displays the TGA curves of the pure PLA and four PLA/NABH samples which exhibit only one mass loss stage of decomposition from TGA curves, and this mass loss stage appears in the temperature range of $300^{\circ} \mathrm{C} \sim 400^{\circ} \mathrm{C}$, which results from chain scissions and combustion of ester groups. Whereas the onset thermal decomposition temperature is affected by $\mathrm{NABH}$, and the onset thermal decomposition temperatures are following: PLLA $341.3^{\circ} \mathrm{C}$, PLLA $/ 0.5 \% \mathrm{NABH} 334.8^{\circ} \mathrm{C}$, PLLA $/ 1 \% \mathrm{NABH} 334.4^{\circ} \mathrm{C}$, PLLA $/ 2 \% \mathrm{NABH} 333.9^{\circ} \mathrm{C}$ and PLLA $/ 3 \%$ $\mathrm{NABH} 331.9^{\circ} \mathrm{C}$. Through data analysis, it is a fact that the presence of NABH weakens the thermal stability of PLLA, but there is no significant decrease, and the maximum difference in onset thermal 
decomposition temperature is less than $10^{\circ} \mathrm{C}$ compared with the pure PLLA. Furthermore, although the onset thermal decomposition temperature decreases with increasing of $\mathrm{NABH}$ loading from $0.5 \mathrm{wt} \%$ to $3 \mathrm{wt} \%$, the difference between all PLLA/NABH samples is only $2.9^{\circ} \mathrm{C}$, indicating that the influence of $\mathrm{NABH}$ loading on the onset thermal decomposition temperature of PLLA/NABH is very slight.

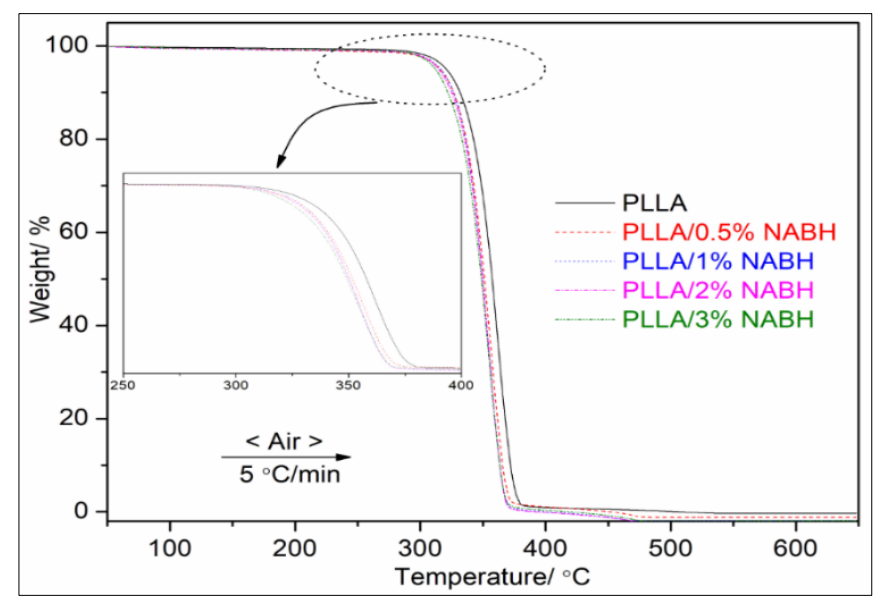

Figure 7. TGA curves of PLLA with and without NABH

Transparency is another important characteristic of PLLA itself, but the addition of a color additive often decreases the light transmittance, affecting its application in some fields. Figure 8 is the effect of $\mathrm{NABH}$ and its loading on PLLA's light transmittance, unfortunately, the introduction of NABH seriously destroys PLLA's light transmittance, when the NABH loading is $0.5 \mathrm{wt} \%$, the light transmittance is decreased to $9.7 \%$ comparing with the $78.2 \%$ of the pure PLLA, what is worse, when the NABH loading is higher than $1 \mathrm{wt} \%$, the light transmittance is almost zero, the primary reason is thought to be the white NABH in PLLA matrix. In addition, the crystallization promoting role of NABH can also make PLLA become opaque to some extent because of crystal formation.

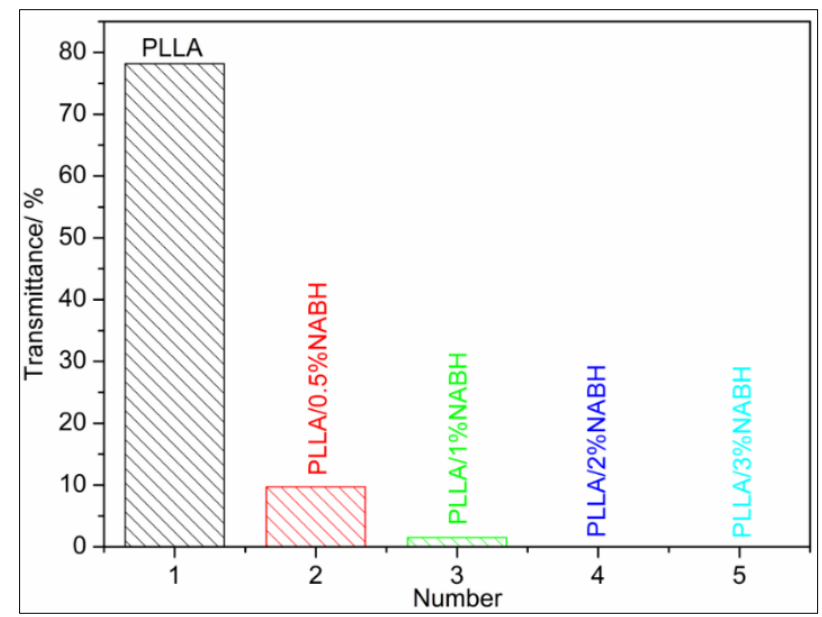

Figure 8 Light transmittance of the pure PLLA and PLLA/NABH

\section{Conclusions}

In conclusion, compared to the pure PLLA, the sharp crystallization peaks of all PLLA/NABH samples indicated that PLLA's crystallization ability was effectively improved by the introduction of $\mathrm{NABH}$ as a new organic heterogeneous nucleating agent. DSC measurements further showed that, upon cooling at $30^{\circ} \mathrm{C} / \mathrm{min}$, PLLA/NABH could still crystallize resulting from the powerful promoting effect of NABH for PLLA's crystallization, although an increase of cooling rate was seriously negative to 
PLLA/NABH's crystallization. Additionally, in melt-crystallization section, the influence of $T_{f}$ on crystallization behavior showed that, when the $T_{f}$ was $170^{\circ} \mathrm{C}$, PLLA/NABH exhibited the highest $T_{o c}$, $T_{m c}$ and the largest $\Delta H_{c}$. The heating rate significantly affected the melting behaviors of NABHnucleated PLLA after melt-crystallization, and a decrease of heating rate could cause the melting peak to become sharper and promote the recrystallization to occur in heating. When the crystallization time was long enough, the melting behavior after isothermal crystallization depended on crystallization temperature. The incorporation of NABH could almost not change thermal decomposition profile of PLLA in air, moreover, the influence of NABH on the onset thermal decomposition temperature of PLLA was also not distinct, which is helpful to satisfy demanding applications. Unfortunately, the light transmittance of PLLA was seriously weakened by the NABH, when the NABH concentration was higher $1 \mathrm{wt} \%$, the light transmission of PLLA/NABH was almost disappeared.

Acknowledgements: This study was supported by Foundation of Chongqing Science and Technology Bureau (cstc2019jcyj-msxmX0876) and Technological Research Program of Chongqing Municipal Education Commission (project number KJQN201801338).

\section{References}

1.CHEN P, ZHOU HF, LIU W, ZHANG M, DU ZJ, WANG XD. The synergistic effect of zinc oxide and phenylphosphonic acid zinc salt on the crystallization behavior of poly (lactic acid) [J], Polymer Degradation and Stability, 2015, 122: 25-35

2.PETCHWATTANA N, NAKNAEN P, NARUPAI B. Combination effects of reinforcing filler and impact modifier on the crystallization and toughening performances of poly(lactic acid) [J], Express Polymer Letters, 2020, 14(9): 848-859

3.FARIA ED, DIAS ML, FERREIRA LM, TAVARES MIB. Crystallization behavior of zinc oxide/poly(lactic acid) nanocomposites [J], Journal of Thermal Analysis and Calorimetry, 2020, DOI: 10.1007/s10973-020-10166-3

4.ZHEN ZY, XING Q, LI RB, DONG X. Crystallization behavior of polylactide nucleated by octamethylenedicarboxylic di(2-hydroxybenzohydrazide): Solubility influence [J], Thermochimica Acta, 2020, 683: 178447

5. XUE B, HE HZ, HUANG ZX, ZHU ZW, LI JQ, ZHAN ZM, CHEN M, WANG GZ, XIONG CT. Morphology evolution of poly(lactic acid) during in situ reaction with poly(butylenesuccinate) and ethylene-methyl acrylate-glycidyl methacrylate: The formation of a novel 3D star-like structure [J], Journal of Applied Polymer Science, 2020, 137(40): e49201

6. FOGLIA F, DE MEO A, IOZZINO V, VOLPE V, PANTANI R. Isothermal crystallization ofPLA: Nucleation density and growth rates of alpha and alpha' phases [J], Canadian Journal of Chemical Engineering, 2020, 98: 1998-2007

7. SOMSUNAN R, MAINOIY N. Isothermal and non-isothermal crystallization kinetics of PLA/PBS blends with talc as nucleating agent [J], Journal of Thermal Analysis and Calorimetry, 2020, 139(3): 1941-1948

8. NIKVARZ N, KHAYATI GR, SHARAFI S. Preparation of UV absorbent films using polylactic acid and grape syrup for food packaging application [J], Materials Letters, 2020, 276: 128187

9. GONZALEZ EAS, OLMOS D, LORENTE MA, VELAZ I, Gonzalez-Benito J. Preparation and characterization of polymer composite materials based on $\mathrm{PLA} / \mathrm{TiO}_{2}$ for antibacterial packaging [J], Polymers, 2018, 10(12): 1365

10. MULLER J, GONZALEZ-MARTINEZ C, CHIRALT A. Combination of poly(lactic) acid and starch for biodegradable food packaging [J], Materials, 2017, 10(8): 952

11. HUANG QL, LIU YS, OUYANG ZX, FENG QL. Comparing the regeneration potential between PLLA/Aragonite and PLLA/Vaterite pearl composite scaffolds in rabbit radius segmental bone defects [J], Bioactive Materials, 2020, 5(4): 980-989 
12. RAMOS M, BELTRAN A, FORTUNATI E, PELTZER M, CRISTOFARO F, Visai L, VALENTE AJM, JIMENEZ A, KENNY JM, GARRIGOS MC. Controlled release of thymol from poly(lactic acid)based silver nanocomposite films with antibacterial and antioxidant activity [J], Antioxidants, 2020, 9(5): 395

13.YANG FH, NIU XF, GU XN, XU CP, WANG W, FAN YB. Biodegradable magnesium-incorporated poly(L-lactic acid) microspheres for manipulation of drug release and alleviation of inflammatory response [J], ACS Applied Materials \& Interfaces, 2019, 11(26): 23546-23557

14. MARCONI PL, TRENTINI A, ZAWOZNIK M, NADRA C, MERCADE JM, NOVOA JGS, OROZCO D, GROPPA MD. Development and testing of a 3D-printable polylactic acid device to optimize a water bioremediation process [J], AMB Express, 2020, 10(1): 142

15. ZHANG HG, ZHONG WU, HU QX, ABURAIA M, GONZALEZ-GUTIERREZ J, LAMMER H. Research and implementation of axial 3D printing method for PLA pipes [J], Applied Science-Basel, 2020, 10(13): 4680

16]. LIAO JJ, BROSSE N, PIZZI A, HOPPE S, ZHOU XJ, DU GB. Characterization and 3D printability of poly (lactic acid)/acetylated tannin composites [J], Industrial Crops and Products, 2020, 149: 112320 17. LIU WL, ZHANG H, ZHANG W, WANG M, LI JH, ZHANG Y, LI HY. Surface modification of a polylactic acid nanofiber membrane by zeolitic imidazolate framework- 8 from secondary growth for drug delivery [J], Journal of Materials Science, 2020, 55(31): 15275-15287

18]. HUERTA-CARDOSO O, DURAZO-CARDENAS I, LONGHURST P, SIMMS NJ, ENCINASOROPESA A. Fabrication of agave tequilana bagasse/PLA composite and preliminary mechanical properties assessment [J], Industrial Crops and Products, 2020, 152: 112523

19. LI HB, HUNEAULT MA. Effect of nucleation and plasticization on the crystallization of poly(lactic acid) [J], Polymer, 2007, 48(23): 6855-6866

20. HARRIS AM, LEE EC. Improving mechanical performance of injection molded PLA by controlling crystallinity [J], Journal of Applied Polymer Science, 2008, 107(4): 2246-2255

21. DAY M, NAWABY AV, LIAO X. A DSC study of the crystallization behaviour of polylactic acid and its nanocomposites [J], Journal of Thermal Analysis and Calorimetry, 2006, 86(3): 623-629

22. SUKSUT B, DEEPRASERTKUL C. Effect of nucleating agents on physical properties of poly(lactic acid) and its blend with natural rubber [J], Journal of Polymers and the Environment, 2011, 19(1): 288296

23. ZOU GX, ZHANG X, LI BJ, ZHAO CX, LI JC. Effect of mineral fillers on crystallization and melting behavior of poly(lactid acid)/mineral filler composites [J], Acta Polymerica Sinica, 2012, 9: 952-957

24. WANG SS, HAN CY, BIAN JJ, HAN LJ, WANG XM, DONG LS. Morphology, crystallization and enzymatic hydrolysis of poly(L-lactide) nucleated using layeredmetal phosphonates [J], Polymer Interantional, 2011, 60: 284-295

25. CAI YH, ZHAO LS. Magnesium phenylphosphonate: A additive for poly(L-lactic acid) [J], Materials Research Express, 2017, 4(3): 035305

26. ZHAO Y, LIU B, YOU C, CHEN MF. Effects of MgO whiskers on mechanical properties and crystallization behavior of PLLA/MgO composites [J], Materials and Design, 2016, 89: 573-581

27. CHEN RY, ZOU W, WU CR, JIA SK, HUANG Z, ZHANG GZ, YANG ZT. Poly(lactic acid)/poly(butylene succinate)/calcium sulfate whiskers biodegradable blends prepared by vane extruder: Analysis of mechanical properties, morphology, and crystallization behavior [J], Polymer Testing, 2014, 34: 1-9

28. SONG P, CHEN GY, WEI ZY, CHANG Y, ZHANG WX, LIANG JC. Rapid crystallization of poly(L-lactic acid) induced by a nanoscaled zinc citrate complex as nucleating agent [J], Polymer, 2012, 53(19): 4300-4309

29. GONG XH, PAN L, TANG CY, CHEN L, LI CQ, WU CG, LAW WC, WANG XT, TSUI CP, XIE $\mathrm{XL}$. Investigating the crystallization behavior of poly(lactic acid) using CdSe/ZnS quantum dots as heterogeneous nucleating agents [J], Composites Part B-Engineering, 2016, 91: 103-110 
30. KAWAMOTO N, SAKAI A, HORIKOSHI T, URUSHIHARA T, TOBITA E. Physical and mechanical properties of poly(L-lactic acid) nucleated by dibenzoylhydrazide compound [J], Journal of Applied Polymer Science, 2007, 103(1): 244-250

31. ZOU GX, JIAO QW, ZHANG X, ZHAO CX, LI JC. Crystallization behavior and morphology of poly(lactic acid) with a novel nucleating agent [J], Journal of Applied Polymer Science, 2015, 132(5): 41367

32. LAI WC, LIAO JP. Nucleation and crystal growth kinetics of poly(L-lactic acid) with self-assembled DBS nanofibrils [J], Materials Chemistry and Physics, 2013, 139(1): 161-168

33. YOU JX, YU W, ZHOU CX. Accelerated crystallization of poly(lactic acid): Synergistic effect of poly(ethylene glycol), dibenzylidene sorbitol, and long-chain branching [J], Industrial \& Engineering Chemistry Research, 2014, 53(3): 1097-1107

34. ZHAO LS, CAI YH. A 1H-benzotriazole derivative nucleated poly(L-lactic acid): Thermal behavior and physical properties [J], Journal of the Chemical Society of Pakistan, 2020, 42(3): 383-389

35. CAI YH, TANG Y, ZHAO LS. Poly(L-lactic acid) with organic nucleating agent $N, N$, $N$ '-tris $(1 \mathrm{H}-$ benzotriazole) trimesinic acid acethydrazide: Crystallization and melting behavior [J], Journal of Applied Polymer Science, 2015, 132(32): 42402

36. FAN YQ, ZHU J, YAN SF, CHEN XS, YIN JB. Nucleating effect and crystal morphology controlling based on binary phase behavior between organic nucleating agent and poly(L-lactic acid) [J], Polymer, 2015, 67: 63-71

37. ZHAO LS, CAI YH, LIU HL. Physical properties of poly(L-lactic acid) fabricated using salicylic hydrazide derivative with tetraamide structure [J], Polymer-Plastics Technology and Materials, 2020, 59(2): 117-129

38. SU ZZ, GUO WH, LIU YJ, LI QY, WU CF. Non-isothermal crystallization kinetics of poly(lactic acid)/modified carbon black composite [J], Polymer Bulletin, 2009, 62: 629-642

39. CAI YH, ZHAO LS. Investigating on the modification of $N, N^{\prime}$-adipic bis(benzoic acid) dihydrazide on poly (L-lactic acid) [J], Polymer Bulletin, 2019, 76(5): 2295-2310

40. WU T, TONG YR, QIU F, YUAN D, ZHANG GZ, QU JP. Morphology, rheology property, and crystallization behavior of PLLA/OMMT nanocomposites prepared by an innovative eccentric rotor extruder [J], Polymers for Advanced Technologies, 2018, 29(1): 41-51

$\overline{\text { Manuscript received: } 23.11 .2020}$ 